\title{
Characterising the morphological properties and surface composition of radium contaminated particles: a means of interpreting origin and deposition.
}

Clare A. Wilson, ${ }^{* a}$ W. Paul Adderley, ${ }^{a}$ Andrew N. Tyler ${ }^{a}$ and Paul Dale ${ }^{b}$

5

\author{
a Biological and Environmental Sciences, School of Natural Sciences, University of Stirling, Stirling, \\ FK9 4LA, United Kingdom \\ ${ }^{\mathrm{b}}$ Scottish Environment Protection Agency, Erskine Court, Stirling, FK9 4TR, United Kingdom \\ * Corresponding author: 44 (0)1786 467817; E-mail: c.a.wilson@stir.ac.uk
}

Table of Contents Entry

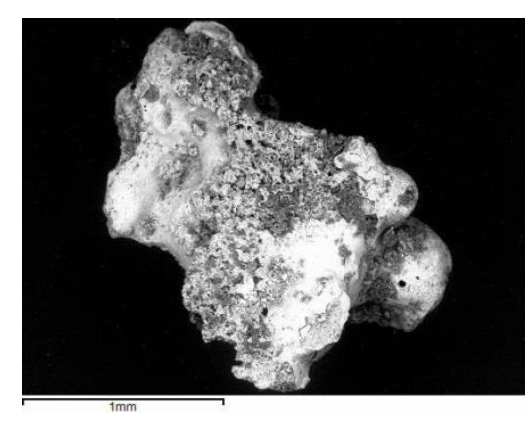

This research applies a novel combination of optical microscopy and SEM-EDX analysis to characterise the morphology and surface composition of environmental 'hot particles'. These widely available techniques offer a means to help identify the source and origin of particles, the way in which they have been deposited, and the potential for their movement and redistribution.

\section{Abstract}

Radioactive 'hot particles' that occur in the environment present specific challenges for health and environmental regulators as often their small size makes them difficult to detect, and they are easily dispersed and accidentally ingested or inhaled by members of the public. This study of nine hot particles recovered from the beach at Dalgety Bay, UK, uses a combination of gamma spectrometry, imaging microscopy and SEM-EDX in order to characterise their morphology and surface composition, thereby helping to identify their origin and source characteristics. The nine particles analysed showed great heterogeneity in their activities, physical form and elemental composition. The particle activities were dominated by ${ }^{226} \mathrm{Ra}$ and its daughters. Three distinct grouping of particles were identified based on their morphology (artefact, glassy and 'metal-rich'), whilst four distinct groupings (artefact, glassy, angular and porphyric, rounded and highly porous) were identified based on morphology and surface properties as seen in the SEM. Whilst the 'artefact' particles were little altered, the other particles showed evidence of incineration. All particles were in a size and / or 
shape class vulnerable to wind- or water-mediated transport. No correlations were found between morphology and chemical composition. SEM-EDX analysis revealed $\mathrm{C}, \mathrm{Si}, \mathrm{Zn}, \mathrm{Fe}, \mathrm{Ca}$ are common in the particles together with $\mathrm{Ba}, \mathrm{Ni}, \mathrm{Pb}, \mathrm{Cu}, \mathrm{Mn}$ and $\mathrm{Ti}$. This is interpreted as the particles being derived from radium containing luminescent paint containing a $\mathrm{Zn} / \mathrm{S}$ phosphor, a hydrocarbon base and other fillers and additives. Evidence of copper and steel alloys were also present in some particles, whilst one consisted of a hydrocarbon based 'capsule'. The combination of techniques employed here has enabled interpretation of the origins of the radioactive particles and given insights into the potential movement of particles within the local environment.

\section{Introduction}

High activity, environmental radioactive particles (hot particles) have been found at locations around the globe. These discrete, non-homogeneous particles are derived mainly from nuclear weapons testing and the nuclear energy production ${ }^{1}$. Particles have been identified linked to depleted uranium weapons ${ }^{2,3,4}$, plutonium and uranium bearing particles from weapons testing ${ }^{5,6}$, accidental releases from weapons ${ }^{7}$ or nuclear reactors ${ }^{8}$, mining $^{9}$, and nuclear powered satellites ${ }^{10}$. Their small size makes them easily dispersed by wind and water, and difficult to detect and isolate ${ }^{11}$. It may also increase the risk of accidental exposure by inhalation, accidental ingestion, handling, or artefact collection. These potential impacts make determining the origin, depositional history and environmental behaviour of environmental radioactive particles a high priority for researchers and environmental regulators.

Besides gamma and alpha spectrometry methods to identify and quantify radionuclides, a range of techniques are available for further characterising environmental radioactive particles ${ }^{11}$. Whilst traditional spectrometry identifies the radionuclides, it is often useful to further characterise the composition of these particles in order to assess their source and the hazard they pose. Destructive techniques such as sequential extraction and digestion followed by ICP-MS or ICP-OES analysis have been used ${ }^{12,13,14}$; these methods, however, result in radioactive material being lost to the atmosphere and sewerage as waste. Thus, non-destructive techniques are preferred. A wide range of non-destructive methods are available for this purpose. Surface characterisation of elemental and isotopic compositions, and valency have been achieved using SIMS6, PIXIE15, XPS ${ }^{16}$. Confocal and synchrotron $\mu$-XRF have been used for 3D analysis of elemental composition of hot environmental particles ${ }^{6,17}$, whilst synchrotron techniques such as $\mu$-XRD, $\mu$-XANES, $\mu$-XCT can determine the microscale oxidation states, crystallography and tomography of particles ${ }^{4,8,18}$. However, the availability of all these techniques is relatively limited, and their application can be limited by availability, cost, spatial resolution, and the size of particles that can be analysed. In combined analytical approaches SEM-EDX is frequently used to map elemental concentrations across particle surfaces ${ }^{4,6,9}$. The technique is well established, little sample preparation is needed, and the equipment is relatively available and affordable.

World War II and post-war activities at an airfield in Dalgety Bay, Fife have left a legacy of contamination. The presence of radium ( $\mathrm{Ra}$ ) bearing radioactive particles on the beach has been known since at least 1990 ${ }^{19,20}$. Between 1990 and 2012, successive surveys have recovered in excess of 1500 radioactive particles. Of these, 800 Ra contaminated particles were recovered in 2012 during surveys commissioned by the Scottish Environmental Protection Agency (SEPA). 
The study reported here combines imaging microscopy with SEM-EDX analysis in order to characterise the morphology and surface composition of nine of these particles. The aim was to use these characteristics help determine the origin (material source and formation processes) and depositional history of the particles at Dalgety Bay.

\section{Methods}

\section{Site and Sampling}

80 Dalgety Bay is located on the north side of the Firth of Forth in Scotland, UK ( $56^{\circ} 02^{\prime} 03^{\prime \prime} \mathrm{N}$ $\left.3^{\circ} 20^{\prime} 33^{\prime \prime} \mathrm{W}\right)$. The bay itself is approximately $500 \mathrm{~m}$ long, with a sand and shingle beach along its southern edge, and extensive intertidal mud-flats interspersed with rocky outcrops that are exposed at low tide. The club house of a sailing club on the headland to the south east of the bay forms the focal point for the particles recovered (Figure 1). The beach area most affected by the articles has now been effectively closed off to the public through the erection of fences and signage warning of the dangers. Simulated gut digestion work has suggested that if ingested, particles recovered from Dalgety Bay have sufficient activities to deliver a $100 \mathrm{mSv}$ committed effective dose to all age ranges20. The nine high activity particles were amongst those recovered by SEPA from Dalgety Bay in May 2012 within the area highlighted in Figure 1.

\section{Analysis}

The irregular and often complex shape and size of the radium particles and artefacts from $<1 \mathrm{~mm}$ to $>70 \mathrm{~mm}$ in dimensions required a calibration that was as independent of the effects of geometry as possible. The method for achieving this is presented in Tyler et al. ${ }^{20}$ and summarised here. An IAEA RGU (uranium reference material) sample was pelletized into a disk $48 \mathrm{~mm}$ in diameter and $11 \mathrm{~mm}$ in thickness and sealed within a petri dish of similar geometry allowed to equilibrate with the daughters through $222 \mathrm{Rn}$. The RGU pellet was then supported at known distances from the face of a GEM HPGe detector and an efficiency calibration calculated using the natural series lines from ${ }^{214} \mathrm{~Pb},{ }^{214} \mathrm{Bi},{ }^{226} \mathrm{Ra},{ }^{234} \mathrm{Th}$ and ${ }^{210} \mathrm{~Pb}$. The efficiency calibration was then tested with a ${ }^{137} \mathrm{Cs}$ point source of known activity. The optimal calibration distance was determined to be at $300 \mathrm{~mm}$ from the face of the detector, beyond which the $\mathrm{Pb}$ shielding could not be closed. At this distance the efficiency for a ${ }^{137} \mathrm{Cs}$ point source at $661.65 \mathrm{keV}$ was estimated at $0.028 \%$ and the activity was over-estimated by $25 \%$ of the reference value. This systematic uncertainty of $25 \%$ was incorporated into the uncertainty budget and is likely to be a reasonable uncertainty in the activity determination of the radium artefacts for ${ }^{214} \mathrm{Bi}$ and ${ }^{214} \mathrm{~Pb}$. All samples were counted to single percentage 1 sigma Poisson counting uncertainties on the key ${ }^{214} \mathrm{Bi}$ and ${ }^{214} \mathrm{~Pb}$ gamma photon full energy peaks and included in the uncertainty budget. Gamma Vision 32 was used to estimate each particle activity with the efficiency calibration derived from the IAEA RGU pellet.

In this study each of the nine particles were examined optically and images of each particle were captured using an imaging macroscope (Leica M420, Leica Microsystems, Wetzlar, Germany) fitted with an apochromatic objective lens and digital microscope camera (Olympus Colorview III, Olympus Optical, Hamburg, Germany). The nominal magnification of these images ranged from $4 \mathrm{x}$ to $32 \mathrm{x}$. The image scale was calibrated using an optical graticule. Each particle had two or more views taken 
in order to obtain a comprehensive size assessment to ascertain differences in morphology. Images for each axis view were captured as a series of between three and eight frames. Each frame in each series has a different depth of field (also known as z-axis stepped acquisition). For each axis view these frames were combined using a focal-plane merging technique (Extended Focal Imaging algorithm; Soft Imaging System, 2003) to create single two dimensional hyperfocal image with an enhanced depth of focus relative to any single frame. These hyperfocal images have been used as a basis for a set of image analyses involving segmenting each image and calculating size and shape measurements. Image segmentation was based on a simple binary transformation of each image ${ }^{21}$.

Nine size and shape measurements were then calculated using image analysis software (AnalySIS; Soft Imaging System, 2003) to determine ferret maximum $(\mathrm{mm})$, perimeter $(\mathrm{mm})$, convex perimeter $(\mathrm{mm})$, equivalent circle diameter (ECD) $(\mathrm{mm})$, area $\left(\mathrm{mm}^{2}\right)$, convex area $\left(\mathrm{mm}^{2}\right)$, shape, aspect ratio, sphericity and convexity. Several of the shape parameters have been previously used to determine aggregate characteristics in soils ${ }^{22}$.

Each of the nine particles was then individually mounted on an aluminium pin stub using carbon sticky pads. The instrument used was a Zeiss EVO MA-15 variable pressure SEM fitted with an Oxford Instruments X-Max $80 \mathrm{~mm}^{2}$ SDD EDX detector. The analysis was carried out under low vacuum conditions so as to allow analysis of the uncoated samples by protecting against the build-up of static charge on the particle surfaces. Imaging was carried out using a Backscatter Detector (BSE) which gives information on both the topography and composition of the surfaces. Element maps and supplementary point analyses to determine element concentrations were performed using the EDX detector. All analyses were carried out using the conditions outlined in Table 1, and a Co optimisation standard was used to check for beam drift before and after the analysis.

Two surfaces of each particle were imaged and analysed. These were the upper surface (surface 1) relative to the mounting of the particle, and one side surface (surface 2 ). The latter was accessed by rotating and tilting the SEM stage to an angle of between $45^{\circ}$ and $55^{\circ}$. Tilting the stage for analysis of the second surface resulted in unavoidable differences in working distances meaning the quantitative element results had to be normalised to $100 \%$ and thus it is ratios of elements rather than absolute values that can most confidently be interpreted.

The bulk chemical results are based on the mapped data and exclude the direct influence of the carbon sticky pad, the point results are targeted analyses of volumes of surface material ca. 1-2 $\mu \mathrm{m}$ in radius and of a similar depth.

\section{Results}

\section{Particle activities}

Table 2 presents the activity data for each of the nine particles. The activity data shows the presence of ${ }^{226} \mathrm{Ra}$ and its decay daughters: ${ }^{214} \mathrm{~Pb},{ }^{214} \mathrm{Bi}$ and ${ }^{210} \mathrm{~Pb}$. The level of ${ }^{226} \mathrm{Ra}$ activity varies significantly between particles with the highest levels in particle III $(151,000 \mathrm{~Bq})$ more than an order of

150 magnitude greater than in the next most active particle, $\mathrm{VI}(8,300 \mathrm{~Bq})$. The activity order in the particles is III $>$ VI $>$ II $>$ VIII $>$ V $>$ IX $>$ I $>$ IV $>$ VII $(907 \mathrm{~Bq})$. Particle III was imaged following simulated stomach digestion work ${ }^{20}$. 


\section{Optical and SEM Imaging}

Table 3 presents a summary of size and shape results. The hyperfocal images (Figure 2) showed great variation in size measurements. Those with the highest size variation were particles III and V, which both had distinctly cylindrical forms. The variables that explicitly consider shape all show consistent trends (e.g. low shape factor value is consistent with a high aspect ratio value).

Hyperfocal and backscattered electron (BSE) images of each of the particles are presented in Figure 2. The hyperfocal images reveal three different material types in the particles examined, comprising metal-rich sediments (particles I, II, VI, VIII), "glassy" sediment mixtures (particles IV, VII, IX), and particles whose cylindrical morphology is reminiscent of degraded artefacts (particles III, V).

The backscattered electron images reveal information about the finer surface morphology and about the composition of the particles, with dark pixels representing areas of low atomic mass, and light pixels areas of high atomic mass. A group of rounded, amorphous 'glassy' particles with a vesicular structure also identified (particles IV and V) with particles VIII and IX also showing 'glassy' surface characteristics. However, these latter two particles also have characteristics in common with a third group of particles (VI and VII) in being rounded in shape and with highly porous interiors consisting of fine, irregular voids. The final group of particles (I and II) tend to be more angular in shape with a porphyric consistency of fine and larger crystals (ca. $1 \mu \mathrm{m}$ and $>10 \mu \mathrm{m}$ ) embedded in an amorphous matrix.

The BSE SEM images of each of the analysed particles are provided in Figure 3. Particles I and II are distinctive and angular with a porphyric structure consisting of fine and larger crystals (ca. $1 \mu \mathrm{m}$ and $>10 \mu \mathrm{m})$ embedded in an amorphous matrix.

A rounded, vesicular, amorphous 'glassy' structure is evident for particles IV, $\mathrm{V}$ and to a lesser degree VIII and IX. In contrast where particle IX has fractured, the smooth amorphous surface is revealed as a thin surface layer (Figure $3^{*}$ ) overlying a porous and apparently lower atomic weight core. In this respect particle IX appears more similar to particles VI and VII, which also have a rounded morphology, although less smoothed, and a highly porous interior consisting of fine, irregular voids. Particle VIII combines the glassy amorphous appearance of particles IV and V with the rounded morphology of particles VI and VII.

Particle III is very distinctive and has a smooth cylindrical shape with a lip and conical ends; machining marks are evident on the upper surface. The surface composition is relatively amorphous although higher atomic weight particles can be seen adhering to, and embedded within, the surface. At the end of the cylinder, higher atomic weight particles can also be seen either leaking from or embedded in cracks in the surface.

\section{SEM-EDX}

The results of the bulk surface chemical characterisation of each of the particles are given in Table 4. All particles contain $\mathrm{C}, \mathrm{O}, \mathrm{Mg}, \mathrm{Al}, \mathrm{Si}, \mathrm{P}, \mathrm{S}, \mathrm{Ca}$, and $\mathrm{Fe}$. Most particles also contain levels of $\mathrm{Na}, \mathrm{Cl}, \mathrm{K}, \mathrm{Ti}$, $\mathrm{Cu}$ and $\mathrm{Zn}$ detectable by SEM-EDX (>0.01\% weight). Occasional instances of $\mathrm{Cr}, \mathrm{Mn}, \mathrm{Ni}, \mathrm{Co}, \mathrm{As}, \mathrm{Sn}$, $\mathrm{Ba}$ and $\mathrm{Pb}$ were also identified. 
Coarse differences in composition are clear between particle III and the others as this particle surface consists primarily of $\mathrm{C}$ and $\mathrm{O}$ with only trace amounts of other elements. Particle IV is particularly Si rich, particle VII contains high concentrations of $\mathrm{Na}$ and $\mathrm{Cl}$, and particle I contains high levels of $\mathrm{Cu}$. Particle V contains significant quantities of As, whilst particles I and II, and to a more variable extent particles VIII and IX contain more Fe than the other particles. Particles II, VI, VII and IX contain consistently high concentrations of $\mathrm{Zn}$.

These compositional differences were investigated further through element mapping of the particle surface (Figure 4) and point analysis of different surface chemical phases (Table 5). The surface of particle I has three distinct phases; two localised phases are dominated by $\mathrm{Ca}$ or $\mathrm{Si}$, whilst the third phase is dominated by $\mathrm{Cu}$ and extends across the particle surface. Other than the relative concentrations of these three elements, the surface chemistry is similar across the particle with $\mathrm{Cu}$ relatively abundant and $\mathrm{Zn}$ concentrations low in all three phases (Table 5). The surface of particle II contains two chemical phases corresponding with the light and dark phases seen in the BSE image (Figure 3). The main difference between the two phases is the enhanced level of $\mathrm{Zn}$ in the lighter 'grain' structures (Figure 4). Particle III has a very consistent surface chemistry dominated by $\mathrm{C}$ and $\mathrm{O}$ in a 3:1 ratio. However, localised areas of $\mathrm{Zn}, \mathrm{Fe}$, and Si enrichment occur within cracks in the surface, material around the lip of the particle, and isolated grains embedded in the surface of the particle.

The element maps of particle IV showed three distinct chemical phases (Figure 4). The majority of 210 the particles 'glassy' surface is dominated by $\mathrm{Si}$ and $\mathrm{O}$, but also contains significant quantities of $\mathrm{Na}$, $\mathrm{Al}, \mathrm{K}, \mathrm{Ca}, \mathrm{Fe}, \mathrm{Cu}$ and $\mathrm{Zn}$. Despite the mixed chemistry its composition is relatively homogeneous. A Fe-rich phase forms a linear phase across the particle surface, whilst localised 'grains' dominated by $\mathrm{Si}$ and $\mathrm{O}$ from the third phase. Very similar Si/O and 'glassy' Zn-rich phases are present in particle $\mathrm{V}$, apparent $\mathrm{Al}$ and $\mathrm{Zn}$ concentrations shown in the element maps appear to be topographic artefacts in the point analysis results (Table 5).

Element maps of the surface of particle VI show a relatively homogeneous composition. In the BSE image a light and dark phase are evident, with the light phase occurring wherever the irregular porous interior is exposed. The main chemical difference between the phases is higher $\mathrm{Zn}$, and to a lesser extent $\mathrm{Cu}$, concentrations in the bright phase. On the surface of particle VII, the distribution of $\mathrm{Na}$ and $\mathrm{Cl}$ are strongly correlated indicating the presence of $\mathrm{NaCl}$ salts in the dark areas seen in the BSE image. The rest of the particle surface contains high concentrations of $\mathrm{Zn}$ and $\mathrm{Fe}$, and also $\mathrm{S}$ and Ba. Particle VIII also has a 'dark' NaCl phase, however unlike particle VII, particle VIII is Si rich with lower quantities of $\mathrm{Ca}$ and $\mathrm{Ba}$. $\mathrm{Zn}$ is only present as a trace element in this particle. The element maps for particle IX highlighted localised areas of elevated Al and Fe concentrations, whilst other elements such as $\mathrm{Zn}$ appear to be more uniformly distributed across the surface. BSE image also identified a bright phase that appears to be a coating on the particle surface. This surface coating contains elevated levels of $\mathrm{Si}$ and $\mathrm{Zn}$ compared to the rest of the particle surface, and also contains significant quantities of $\mathrm{Pb}$. Fe is present in the coating but at lower relative levels than in the rest of the particle, which besides $\mathrm{C}$ is also $\mathrm{Zn}$ rich.

\section{Discussion}


The activity of all of the Dalgety Bay particles is dominated by ${ }^{226} \mathrm{Ra}$. Discovered in the late $19^{\text {th }} \mathrm{C}$ Ra was soon used in a number of health and industrial products, including luminescent paint produced by combining ${ }^{226} \mathrm{Ra}$, zinc sulphide and glue. Production of Ra containing luminescent paint peaked during the Second World War when it was used extensively in military instrument dials ${ }^{23}$.

Despite Ra being recognised through Total Activity measurements ${ }^{19,20}$, no Ra was identified by SEMEDX, but as the detection limits are in the order of $0.01 \%$ weight, it is likely that the levels were simply too low to detect by this method. The concentrations of Ra used in luminous paints were variable with reports of between 1:140,000 and 1:53,000 Ra to base $(\mathrm{ZnS})^{24}$. There were hints of the presence of $\mathrm{Bi}$ and $\mathrm{Ra}$ in the spectrum of many particles but these were not strong enough to distinguish them statistically from the background bremsstrahlung $X$-rays that are produced by the electron beam interaction with the surface ${ }^{25}$.

Particles II, IV, V, VI, VII and IX all have a broadly similar composition. In all these particles C, $\mathrm{Si}, \mathrm{Zn}, \mathrm{Fe}, \mathrm{Ca}$ are common components together with $\mathrm{Ba}, \mathrm{Ni}, \mathrm{Pb}, \mathrm{Cu}, \mathrm{Mn}$ and Ti. With the exception of relatively low $S$ concentrations, this elemental profile is consistent with $\mathrm{ZnS}$ paints ${ }^{26,27}$, including radioluminescent paints. Such paints frequently contained $\mathrm{Cu}, \mathrm{Mn}$ and other additives to alter their colour, luminescence, stability and viscosity and flow properties. The high $\mathrm{C}$ concentrations are consistent with the hydrocarbon based glue component used in such paints, and Si with the silicates and $\mathrm{SiO}_{2}$ used as a paint filler or pigment, or to increase the thermal stability of $\mathrm{ZnS}: \mathrm{Mn}$ films ${ }^{28}$.

Particle IX has a distinctive surface coating containing $\mathrm{Pb}$ as well as $\mathrm{C}, \mathrm{Si}, \mathrm{Zn}, \mathrm{Ca}$ and $\mathrm{Fe}$. These results are consistent with the findings of previous studies of $\mathrm{Pb}$ based paint ${ }^{26,27}$. This particle also contains a distinctive Fe-Zn dominated phase that runs directly across its surface. This phase appears to represent either a fragment of galvanised steel or an anti-corrosion Fe-Zn alloy.

In contrast, particles I and VIII do not contain a significant proportion of $\mathrm{Zn}$ ( $>1 \%$ weight). Particle I is 255 dominated by $\mathrm{Cu}$, whilst particle VIII appears to be predominantly carbon based. However, both still contain the suite of metals, $\mathrm{Si}$ and $\mathrm{C}$ expected from a paint source. $\mathrm{Cu}$ is known to have been used as a doping agent in some luminescent $\mathrm{ZnS}$ paints ${ }^{28}$, but whilst the traces of $\mathrm{Cu}$ identified in particles VII, VIII and IX may be from a paint source, the high Cu concentrations in particle I suggest the inclusion of Cu metal in this instance.

260 The $\mathrm{O} / \mathrm{C}$ ratio of the capsule body of particle III is 1:3, in the range expected of polystyrene, PVC and other plastics ${ }^{29}$. The traces of $\mathrm{Si}, \mathrm{Al}$ and Fe found across the main body of the capsule could all originate as contamination from the beach environment. However, the $\mathrm{Zn}$ and Fe rich materials found within the cracks on the end of the particle are distinctive. It's not possible to say whether these materials have leaked from the interior of the capsule, or have been embedded in the surface 265 of the particle either during use of post-burial. The composition of the $\mathrm{Zn}$ rich phase in the cracks of the particle also suggests a ZnS paint based origin, whilst the Fe rich phase appears to be dominated by Fe oxides.

The morphological characteristics of particle III clearly mark it out as a relatively unaltered 'artefact', whilst the hyper-focal optical images also showed $V$ to have a cylindrical form indicating this to be an altered 'artefact'. The remaining particles had variously rounded or angular morphologies, with combinations of 'glassy', vesicular, porous and porphyric characteristics. The glassy, vesicular and porous characteristic, variously seen in all the particles except particle III, are 
typical of ash / waste particles from incineration processes ${ }^{30}$. The possibility of incineration is further supported by the presence of crystals of $\mathrm{SiO}_{2}$ in porphyric particles I and II. Quartz is stable at temperature below $870^{\circ} \mathrm{C}$ and melt at $1720^{\circ} \mathrm{C}$ at atmospheric pressure ${ }^{31}$, so if this is the case it suggests that at least some of the particles have been subject to very high temperatures. Anecdotal evidence from Dalgety Bay suggests that incineration of luminescent materials from the redundant aircraft was common ${ }^{19}$. The evidence from this study supports this story and means that the potential implications of incineration on the Ra compounds requires further study in order to characterise and understand the hazard presented. Incineration could also account for the low concentration of $\mathrm{S}$ as this would have been lost as $\mathrm{SO}_{2}$ during combustion. $\mathrm{NaCl}$ deposits on the surface of particles VII and VIII appear to be post-depositional deposits resulting from the evaporation of sea water from their surface.

Excluding particle III, all the particles fall into the size category of sand materials (63-2000 $\mu \mathrm{m})$, in this respect the ECD measurement is perhaps the most useful variable to assess size as these values typically showed low deviations. Sample sizes are too small to suggest that the shape is related to particle composition, but there is an apparent trend of the apparently "glassy" materials showing least sphericity.

The size range of the particles (Table 3) suggests that depending upon the density of these particles, and with the exception of particle III, all could be subject to movement by wind-induced saltation processes $^{32}$. The more spherical and rounded particles, including particles II, VIII and even III, might also be subject to wind and water induced rolling processes. Understanding these processes with respect to the movement of radioactive particles is an area that warrants further research. With larger sample numbers sediment transport modelling could be used to predict the likelihood of sediment transport for different types of debris materials, and thus to quantify the dynamic nature and possible spread of the hazard within and around the Dalgety Bay beach area.

The aim of this study was to use readily available, non-destructive techniques to characterise the particles. However, as SEM-EDX only characterises surface composition, future analysis to determine the bulk chemistry of the particles would be useful as the composition of the particle interiors and surfaces cannot be assumed to be identical. The presence of $\mathrm{NaCl}$ coatings, as on particles VII and VIII for example, could mask the true nature of the particle composition. Techniques such as microFT-IR should also be examined as a means of providing complementary information on chemical composition through the identification of functional groups.

\section{Conclusions}

The nine sand-sized or larger particles analysed revealed a varied selection of morphological and chemical characteristics. There was no apparent correlation between morphology and composition, the latter being linked more to the degree and nature of alteration of the original materials. The origin of the particles appears to be radium containing luminescent paint together with fragments of steel, and copper, as well as quartz from the local environment. All particles appear to have been subject to incineration with the exception of particle III which is a relatively unaltered plastic based capsule from which $\mathrm{ZnS}$ radium paint appears to be leaking. It is also possible that all the particles 
could be subject to further wind or water mediated distribution within the local environment by saltation or rolling processes.

This study has utilised relatively widely available analytical methods in order to characterise the morphological properties and surface characteristics of Ra containing particles recovered from Dalgety Bay, Fife. Although the sample set used was small (nine particles) this analysis has revealed details about the composition, origin, formation and depositional environment of these particular particles that have implications for the hazard they pose and management of the site.

\section{Acknowledgements}

This work was funded by the Scottish Environmental Protection Agency (SEPA) UK. Special thanks go to Stuart Bradley, University of Stirling for technical assistance in the handling and analysis of the radioactive particles.

\section{References}

1. S. Török, J. Osán, L. Vincze, B. Alföldy, A. Kerkápoly, N. Vajda, C. A. Pérez and G. Falkenberg, Comparison of nuclear and X-ray techniques for actinide analysis of environmental hot particles, $J$. Anal. At. Spectrom., 2003, 18, 1202-1209.

330 2. P.R. Danesi, A. Markowicz, E. Chinea-Cano, W. Burkart, B. Salbu, D. Donohue, F. Ruedenauer, M. Hedberg, S. Vogt, P. Zahradnik and A. Ciurapinski, Depleted uranium particles in selected Kosovo samples, J. Environ. Radioact., 2003, 64, 143-154.

3. B. Salbu, K. Janssens, O.C. Lind, K. Proost, and P.R. Danesi, Oxidation states of uranium in DU particles from Kosovo, J. Environ. Radioact., 2003, 64, 167-173.

335 4. B. Salbu, K. Janssens, O.C. Lind, K. Proost, L. Gijsels and P.R. Danesi, Oxidation states of uranium in depleted uranium particles from Kuwait, J. Environ. Radioact., 2005, 78, 125-135.

5. J. Jernström, M. Eriksson, R. Simon, G. Tamborini, O. Bildstein, R. Carlos Marquez, S. R. Kehl, T. F. Hamilton, Y. Ranebo, and M. Betti, Characterisation and source term assessments of radioactive particles from Marshall Islands using non-destructive analytical techniques, Spectrochim. Acta, Part B, 2006, 61, 971-979.

6. T. F. Hamilton, J. Jernströem, R. E. Martinelli, S. R. Kehl, M. Eriksson, R. W. Williams, M. Bielewski, A. N. Rivers, T. A. Brown, S. J. Tumey and M. Betti, Frequency distribution, isotopic composition and physical characterization of plutonium-bearing particles from the Fig-Quince zone on Runit Isalnd, Enewetak Atoll, J. Radioanal, Nucl. Chem., 2009, 282, 1019-1026.

345 7. A. Aragón, A. Espinosa, B. de la Cruz and J. A. Fernández, Characterization of the radioactive particles from the Palomares accident, J. Environ. Radioact., 2008, 99, 1061-1067.

8. B. Salbu, T. Krekling, O.C. Lind, D. H. Oughton, M. Drakopoulos, A. Simionovici, I. Snigireva, A. Snigirev, T. Weitkamp, F. Adams, K. Janssens and V. A, Kashparov, High energy X-ray microscopy for 
characterisation of fuel particles, Nucl. Instrum. Methods Phys. Res., Sect. A, 2001, 467-468, 12491252.

9. E. A. Stefaniak, A. Alsecz, R. Frost, Z. Máthé, I. E. Sajó, S. Török, A. Worobiec and R. Van Grieken, Combined SEM/EDX and micro-Raman spectroscopy analysis of uranium materials from a former uranium mine, J. Hazard. Mater., 2009, 168, 416-423.

10. B. Salbu, Actinides associated with particles, in Plutonium in the Environment, ed. A. Kudo, Elsevier, Amsterdam, 2001, 121-138.

11. M. Betti, M. Eriksson, J. Jernström, G. Tamborini, Environmental radioactive particles: a new challenge for modern analytical instrumental techniques in support of radioecology, Radioact. Environ., 2008, 11, 355-370.

12. N. Yanase, H. Isobe, T. Sato, Y. Sanada, T. Matsunaga and H. Amano, Characterization of hot particles in surface soil around the Chernobyl NPP, J. Radioanal. Nucl. Chem., 2002, 252, 233-239.

13. T. Shinonaga, F. Esaka, M. Magara, D. Klose and D. Donohue, Isotopic analysis of single uranium and plutonium particles by chemical treatment and mass spectrometry, Spectrochim. Acta Part B, $2008,63,1324-1328$.

14. C. P. Huang, T. Y. Lin, L. H. Chiao and H. B. Chen, Characterization of radioactive contaminants and water treatment trials for the Taiwan Research Reactor's spent fuel pool, J. Hazard. Mater., 2012, 233-234, 140-147.

15. M. C. Jiménez-Ramos, J. García-López, R. García-Tenorio and M. García-León, Characterization of terrestrial hot particles from the Palomares accident using destructive and non-destructive analytical techniques, Radioprotection, 2009, 44, 345-350.

16. P. Kádár, K. Varga, B. Baja, Z. Németh, N. Vajda, Zs. Stefánka, L. Köver, I. Csermy, J. Tóth, T. Pintér, and J. Schunk, Accumulation of uranium, transuranium and fission products on stainless steel surfaces, II. Sorption studies in a laboratory model system, J. Radioanal. Nucl. Chem., 2011, 288, 943954.

17. M. Bielewski, M. Eriksson, J. Himbert, R. Simon, M. Betti and T. F. Hamilton, Confocal $\mu-X R F$ for $3 D$ analysis of elements distribution in hot environmental particles, Annual report of the Synchrotron Facility, 2007, Anka, Forschungszentrum Karlsruhe, Germany.

18. O. C. Lind, B. Salbu, L. Skipperud, K. Janssens, J. Jaroszewicz and W. de Nolf, Solid state speciation and potential bioavailability of depleted uranium particles from Kosovo and Kuwait, J. Environ. Radioact., 2009, 100, 301-307.

19. P. Dale, Dalgety Bay radium contamination, Report by Scottish Environmental Protection Agency (SEPA), 2012.

20. A. N. Tyler, P. Dale, D. Copplestone, S. Bradley, H. Ewen, C. McGuire and E.M. Scott. The radium legacy: contaminated land and the committed effective dose from the ingestion of radium contaminated materials, Environ. Int., 2013, 59, 449-455. 

pp.771.

22. W. R., Whalley, B. Riseley, P.B. Leeds-Harrison, N. R. A. Bird, P. K. Leech and W. P. Adderley, Structural differences between bulk and rhizosphere soil, Eur. J. Soil Sci., 2005, 56, 353-361.

23. R. M. Pratt, Review of radium hazards and regulation of radium in industry, Environ. Int., 1993, 19, 475-493.

24. E. J. Boesch, M.S, Raber, G. Weinstein and T. R. Flagg, Paint Application Building, U.S. Radium Corporation Site - Photographs, HAER No. NJ-121, Historic American Engineering Record, Philadelphia, 1999.

25. V. V. Ivin, M. V. Silakov, D. S. Kozlov, K. J. Nordquist, B. Lu and D. J. Resnick, The inclusion of secondary electrons and Bremsstrahlung X-rays in an electron beam resist model, Microelectron. Eng., 2002, 61-62, 343-349.

26. B. L. Gulson, J. J. Davis and J. Bawden-Smith, Paint as a source of recontamination of houses in urban environments and its role in maintaining elevated blood levels in children, Sci. Total Environ., 1995, 164, 221-235.

400 27. H. W. Mielke, E. T. Powell, A. Shah, C. R. Gonzales and P.W. Mielke, Multiple metal contamination from house paints: consequences of power sanding and scraping in New Orleans, Environ. Health Perspect., 2001, 109, 973-978.

28. H. Kubo, T. Isobe, H. Takahashi and S. Itoh, Characterization of the thermal stability of $\mathrm{ZnS}: \mathrm{Mn2}^{+} / \mathrm{MPS} / \mathrm{SiO}_{2}$ nano-phosphor film, Appl. Surf. Sci., 2005, 244, 465-468.

29. L. H. Sperling, Introduction to physical polymer science, 2006 New Jersey, John Wiley \& Sons.

30. B. Gagnepain, R. Flamond, D. Gauthier and G. Flamant, Charaterization of $\mathrm{Cr}, \mathrm{Pb}$, and $\mathrm{Zn}$ in municipal waste incinerator ashes by microscopic and spectroscopic methods, in Use of incinerator ash, eds. R. K. Dhir, T. D. Dyer and K. A. Paine, Thomas Telford Publishing, London, 2000, 55-66.

31. G. Devoud, C. Hayzelden, M. J, Aziz and D. Turnbull, Growth of quartz from amorphous silica at ambient pressure, J. Non-Cryst. Solids, 1991, 134, 129-132.

32. T. E. Barchyn and C. H. Hugenholtz, Comparison of four methods to calculate aeolian sediment transport threshold from field data: Implications for transport prediction and discussion of method evolution, Geomorphology, 2011, 129, 190-203. 
Table 1: SEM and EDX analytical protocols

\begin{tabular}{ll} 
Parameter & Setting \\
\hline Chamber Pressure & $60 \mathrm{~Pa}$ \\
Magnification & X 75-X200 \\
Filament Current & $2.770 \mathrm{~A}$ \\
Beam Current & $50 \mathrm{\mu A}$ \\
Iprobe Current & $495 \mathrm{pA}$ \\
Accelerating Voltage & $20 \mathrm{kV}$ \\
Working Distance & $8.5 \mathrm{~mm}$ (where possible) \\
X-ray Acquisition Rate & $8.5-10 \mathrm{kcps}$ \\
EDX spectrum counts & Ca. 2 million \\
EDX live time & 45 seconds
\end{tabular}

425

Table 2: The total activity $(\mathrm{Bq})$ for each of the Dalgety Bay particles

\begin{tabular}{|c|c|c|c|c|c|c|c|c|c|c|}
\hline \multirow[b]{2}{*}{$\begin{array}{c}\text { Particle } \\
\text { ID }\end{array}$} & \multicolumn{2}{|c|}{ Dimension } & \multicolumn{8}{|c|}{ Total Activity $\mathrm{Bq}$ and 2 sigma measurement uncertainty (\%) } \\
\hline & $\underset{\mathrm{mm}}{\mathrm{X}}$ & $\begin{array}{c}\mathrm{Y} \\
\mathrm{mm}\end{array}$ & ${ }^{226} \mathrm{Ra}$ & $\%$ & ${ }^{214} \mathrm{~Pb}$ & $\%$ & ${ }^{214} \mathrm{Bi}$ & $\%$ & ${ }^{210} \mathrm{~PB}$ & $\%$ \\
\hline I & $<1$ & $<1$ & 1,680 & 30.1 & 1,980 & 28.1 & 1,990 & 28.1 & 1,780 & 31.0 \\
\hline II & 1 & 1 & 6,180 & 36.8 & 7,230 & 35.2 & 6,830 & 35.2 & 7,160 & 37.5 \\
\hline III & 2.0 & 2.0 & 151,000 & 28.4 & 139,000 & 28.0 & 149,000 & 27.9 & 60,500 & 29.0 \\
\hline IV & 1.0 & 0.5 & 1,330 & 28.0 & 1,130 & 23.7 & 1,200 & 24.1 & 1,120 & 26.5 \\
\hline V & 1.0 & 0.5 & 4,790 & 29.2 & 5,520 & 28.3 & 5,620 & 28.3 & 4,300 & 30.0 \\
\hline VI & 0.5 & 0.5 & 8,300 & 28.5 & 10,900 & 27.9 & 10,500 & 28.0 & 10,800 & 28.7 \\
\hline VII & 1 & 1 & 907 & 32.2 & 1210 & 31.7 & 1180 & 31.8 & 1150 & 32.4 \\
\hline VIII & 1 & 1 & 5,440 & 28.0 & 6,130 & 27.9 & 5,930 & 28.0 & 5,660 & 28.1 \\
\hline IX & 2 & 1.5 & 4,160 & 29.4 & 4,990 & 28.0 & 4,860 & 28.1 & 4,630 & 29.5 \\
\hline
\end{tabular}


Table 3: Average size and shape characteristics of Dalgety Bay particles, averages based on at least 3 views, standard deviation is given in brackets.

\begin{tabular}{ccccccccccc} 
Particle & $\begin{array}{c}\text { Feret } \\
\text { max } \\
(\mathrm{mm})\end{array}$ & $\begin{array}{c}\text { Perimeter } \\
(\mathrm{mm})\end{array}$ & $\begin{array}{c}\text { Convex } \\
\text { perimeter } \\
(\mathrm{mm})\end{array}$ & $\begin{array}{c}\text { Area } \\
\left(\mathrm{mm}^{2}\right)\end{array}$ & $\begin{array}{c}\text { Convex } \\
\text { area } \\
\left(\mathrm{mm}^{2}\right)\end{array}$ & $\begin{array}{c}\text { ECD } \\
(\mathrm{mm})\end{array}$ & $\begin{array}{c}\text { Shape } \\
\text { factor }\end{array}$ & $\begin{array}{c}\text { Aspect } \\
\text { ratio }\end{array}$ & Convexity & Sphericity \\
\hline I & 1.41 & 4.49 & 4.09 & 1.02 & 1.09 & 1.09 & 0.58 & 1.38 & 0.92 & 0.48 \\
& $(0.05)$ & $(0.10)$ & $(0.07)$ & $(0.03)$ & $(0.02)$ & $(0.02)$ & $(0.00)$ & $(0.07)$ & $(0.02)$ & $(0.08)$ \\
II & 1.11 & 3.69 & 3.46 & 0.75 & 0.81 & 0.98 & 0.69 & 1.09 & 0.93 & 0.93 \\
& $(0.01)$ & $(0.06)$ & $(0.03)$ & $(0.01)$ & $(0.01)$ & $(0.00)$ & $(0.02)$ & $(0.00)$ & $(0.00)$ & $(0.02)$ \\
III & 5.63 & 31.41 & 17.72 & 19.84 & 21.17 & 5.02 & 0.33 & 1.13 & 0.94 & 0.80 \\
& $(1.06)$ & $(9.32)$ & $(2.08)$ & $(2.41)$ & $(3.51)$ & $(0.30)$ & $(0.21)$ & $(0.10)$ & $(0.04)$ & $(0.18)$ \\
$*$ IV & 1.08 & 6.74 & 3.20 & 0.61 & 0.66 & 0.88 & 0.18 & 1.20 & 0.92 & 0.67 \\
& $(0)$ & $(0.76)$ & $(0.01)$ & $(0.00)$ & $(0.00)$ & $(0.00)$ & $(0.04)$ & $(0.01)$ & $(0.01)$ & $(0.02)$ \\
V & 0.80 & 3.71 & 2.40 & 0.35 & 0.37 & 0.66 & 0.34 & 1.33 & 0.93 & 0.63 \\
& $(0.11)$ & $(0.76)$ & $(0.25)$ & $(0.06)$ & $(0.06)$ & $(0.06)$ & $(0.09)$ & $(0.17)$ & $(0.00)$ & $(0.22)$ \\
$* \mathrm{VI}$ & 0.48 & 2.06 & 1.36 & 0.11 & 0.12 & 0.38 & 0.42 & 1.40 & 0.92 & 0.46 \\
& $(0.01)$ & $(0.57)$ & $(0.00)$ & $(0.00)$ & $(0.00)$ & $(0.00)$ & $(0.22)$ & $(0.10)$ & $(0.01)$ & $(0.05)$ \\
VII & 1.24 & 4.45 & 3.59 & 0.83 & 0.86 & 1.03 & 0.53 & 1.42 & 0.96 & 0.48 \\
& $(0.01)$ & $(0.06)$ & $(0.09)$ & $(0.05)$ & $(0.05)$ & $(0.03)$ & $(0.02)$ & $(0.06)$ & $(0.00)$ & $(0.03)$ \\
VIII & 1.29 & 5.05 & 4.00 & 1.06 & 1.11 & 1.16 & 0.52 & 1.10 & 0.94 & 0.85 \\
& $(0.05)$ & $(0.24)$ & $(0.19)$ & $(0.13)$ & $(0.11)$ & $(0.07)$ & $(0.05)$ & $(0.03)$ & $(0.02)$ & $(0.07)$ \\
IX & 2.01 & 16.62 & 5.79 & 1.76 & 2.13 & 1.50 & 0.12 & 1.52 & 0.83 & 0.41 \\
& $(0.03)$ & $(6.39)$ & $(0.14)$ & $(0.08)$ & $(0.17)$ & $(0.03)$ & $(0.08)$ & $(0.20)$ & $(0.03)$ & $(0.10)$
\end{tabular}

\footnotetext{
* based on 2 views
} 
Table 4: Average surface composition of Dalgety Bay Particles

\begin{tabular}{|c|c|c|c|c|c|c|c|c|c|c|c|c|c|c|c|c|c|c|c|c|c|c|c|}
\hline \multirow{2}{*}{ Sample } & \multicolumn{23}{|c|}{$\%$ Weight } \\
\hline & $\mathrm{C}$ & $\mathrm{O}$ & $\mathrm{Na}$ & $\mathrm{Mg}$ & $\mathrm{Al}$ & $\mathrm{Si}$ & $\mathrm{P}$ & S & $\mathrm{Cl}$ & K & $\mathrm{Ca}$ & $\mathrm{Ti}$ & $\mathrm{Cr}$ & $\mathrm{Mn}$ & $\mathrm{Fe}$ & Co & $\mathrm{Ni}$ & $\mathrm{Cu}$ & $\mathrm{Zn}$ & As & Sn & $\mathrm{Ba}$ & $\mathrm{Pb}$ \\
\hline I & 35.62 & 29.05 & 0.58 & 0.65 & 2.11 & 5.14 & 0.24 & 0.16 & 0.16 & 0.33 & 1.12 & 0.54 & 0.03 & 0.04 & 7.23 & & & 16.02 & 0.93 & & & & \\
\hline II & 38.53 & 26.85 & & 0.95 & 2.57 & 5.09 & 0.06 & 0.12 & & 0.12 & 1.38 & 0.21 & 0.07 & & 7.29 & & 0.04 & 0.07 & 16.28 & & & & \\
\hline III & 68.05 & 30.47 & 0.07 & 0.06 & 0.69 & 0.12 & 0.04 & 0.08 & 0.01 & 0.01 & 0.05 & & & & 0.18 & 0.01 & & 0.11 & 0.13 & & & & \\
\hline IV & 39.15 & 34.95 & 2.69 & 0.54 & 2.73 & 10.49 & 0.10 & 0.15 & 0.27 & 1.36 & 1.01 & 0.12 & & & 2.63 & & & 0.41 & 2.97 & 0.05 & & & 0.40 \\
\hline V & 43.65 & 25.59 & 3.29 & 1.04 & 2.80 & 5.48 & 0.17 & 0.14 & 0.03 & 0.33 & 1.13 & 0.84 & & 0.09 & 3.74 & & & 0.08 & 7.13 & 4.51 & & & \\
\hline VI & 50.66 & 23.98 & & 1.12 & 4.97 & 0.86 & 0.07 & 0.04 & 0.97 & 0.09 & 0.15 & 0.27 & & 0.07 & 1.46 & & 0.02 & 3.87 & 10.77 & 0.01 & 0.21 & & 0.47 \\
\hline VII & 48.32 & 14.59 & 8.59 & 0.54 & 1.03 & 1.57 & 0.08 & 0.52 & 11.72 & 0.22 & 0.32 & 0.07 & & & 1.88 & & & 0.51 & 9.03 & & & 1.03 & \\
\hline VIII & 36.60 & 35.86 & 1.37 & 1.89 & 4.61 & 8.01 & 0.52 & 0.10 & 1.41 & 0.28 & 3.30 & 0.59 & & 0.05 & 5.09 & & 0.07 & 0.12 & 0.20 & & & & \\
\hline IX & 37.99 & 32.28 & & 0.56 & 4.29 & 6.43 & 0.20 & 0.14 & 0.05 & 0.70 & 1.45 & 0.22 & & 0.15 & 4.96 & & & 0.47 & 10.16 & & & & \\
\hline
\end{tabular}


Table 5: Elemental composition of compositional phases across the surface of the Dalgety Bay Particles as determined by SEM-EDX point analysis.

\begin{tabular}{|c|c|c|c|c|c|c|c|c|c|c|c|c|c|c|c|c|c|c|}
\hline \multirow[t]{2}{*}{ Particle } & \multirow[t]{2}{*}{ Phase } & \multicolumn{17}{|c|}{$\%$ Weight } \\
\hline & & $\mathrm{C}$ & $\mathrm{O}$ & $\mathrm{Na}$ & $\mathrm{Mg}$ & $\mathrm{Al}$ & $\mathrm{Si}$ & $\mathrm{P}$ & $S$ & $\mathrm{Cl}$ & $\mathrm{K}$ & $\mathrm{Ca}$ & $\mathrm{Ti}$ & $\mathrm{Fe}$ & $\mathrm{Cu}$ & $\mathrm{Zn}$ & $\mathrm{Ba}$ & $\mathrm{Pb}$ \\
\hline \multirow[t]{3}{*}{ I } & Ca-rich & 37.7 & 26.1 & & 0.7 & 2.1 & 4.6 & 0.4 & 0.2 & & 0.3 & 8.7 & 0.5 & 6.7 & 11.2 & 0.6 & & \\
\hline & Si-rich & 33.2 & 37.3 & & 0.4 & 2.0 & 17.2 & 0.3 & 0.2 & & 0.3 & 1.1 & 0.4 & 2.8 & 3.3 & 0.5 & & \\
\hline & Cu-rich & 29.4 & 30.4 & & 0.5 & 1.7 & 3.5 & 0.2 & 0.2 & & 0.3 & 6.5 & 0.2 & 4.8 & 22.2 & & & \\
\hline \multirow[t]{2}{*}{ II } & Light & 31.0 & 21.3 & & 1.4 & 2.4 & 6.0 & & 0.1 & & & 1.4 & 0.3 & 5.1 & & 32.5 & & \\
\hline & Dark & 34.2 & 25.5 & & 0.9 & 3.2 & 11.7 & & & & 0.3 & 4.0 & 0.3 & 8.0 & & 12.0 & & \\
\hline III & Surface & 74.6 & 25.1 & & & 0.2 & 0.1 & & & & & & & 0.1 & & & & \\
\hline \multirow[t]{3}{*}{ IV } & Si-rich & 37.9 & 36.8 & 0.9 & 0.1 & 0.6 & 20.7 & & 0.1 & 0.1 & 0.4 & 0.3 & & 0.6 & 0.2 & 1.2 & & \\
\hline & Fe-rich & 29.9 & 39.1 & 1.3 & 0.6 & 3.1 & 4.2 & & 0.2 & 0.2 & 0.4 & 0.5 & 0.5 & 18.3 & 0.2 & 2.3 & & \\
\hline & Glassy & 44.7 & 27.1 & 2.3 & 0.5 & 2.8 & 11.5 & & 0.2 & 0.1 & 2.0 & 1.7 & 0.1 & 1.5 & 0.9 & 4.6 & & \\
\hline \multirow[t]{3}{*}{ V } & Surface & 44.9 & 29.0 & & 1.6 & 3.2 & 7.1 & 0.2 & 0.2 & & 0.4 & 1.6 & 0.9 & 3.0 & 0.3 & 7.7 & & \\
\hline & Al-rich & 44.3 & 29.7 & & 1.0 & 2.7 & 3.1 & 0.1 & 0.1 & & 0.2 & 0.9 & 1.2 & 5.5 & 0.3 & 10.9 & & \\
\hline & Si-rich & 43.6 & 34.6 & & 0.3 & 1.4 & 16.7 & & 0.1 & & 0.1 & 0.3 & 0.2 & 1.0 & & 1.8 & & \\
\hline \multirow[t]{2}{*}{ VI } & Light & 48.9 & 16.8 & & 1.0 & 6.1 & 1.0 & & & 1.5 & 0.2 & 0.2 & 0.3 & 1.6 & 6.3 & 16.2 & & \\
\hline & Dark & 45.3 & 29.0 & & 2.7 & 3.9 & 4.5 & 0.2 & 0.1 & 5.6 & 1.1 & 0.2 & 0.2 & 1.2 & 2.2 & 4.1 & & \\
\hline \multirow[t]{2}{*}{ VII } & Light & 41.1 & 17.2 & 3.0 & 0.6 & 1.8 & 1.0 & & 2.1 & 3.6 & 0.2 & 0.3 & & 4.2 & 0.8 & 22.0 & 2.3 & \\
\hline & Dark & 53.2 & 6.8 & 14.3 & 0.2 & 0.3 & 0.4 & & 0.1 & 21.1 & 0.1 & 0.2 & & 0.6 & 0.2 & 2.7 & 0.2 & \\
\hline \multirow[t]{2}{*}{ VIII } & Light & 41.8 & 36.2 & 0.7 & 1.5 & 4.6 & 7.2 & 0.3 & 0.2 & 0.4 & 0.2 & 3.3 & 0.3 & 3.2 & 0.4 & 0.3 & & \\
\hline & Dark & 54.7 & 28.1 & 4.1 & 0.6 & 2.1 & 3.3 & 0.1 & 0.1 & 4.0 & 0.1 & 1.1 & 0.1 & 1.7 & & & & \\
\hline \multirow[t]{3}{*}{ IX } & Surface & 52.6 & 27.7 & & 0.6 & 1.7 & 3.1 & 0.2 & 0.4 & 0.3 & 0.5 & 1.7 & & 2.7 & 0.4 & 6.5 & & \\
\hline & Coat & 38.1 & 31.0 & & 0.6 & 2.1 & 10.3 & & & & 1.2 & 1.5 & & 2.2 & 1.2 & 11.0 & & 1.4 \\
\hline & Fe-rich & 28.0 & 36.3 & & 0.6 & 3.8 & 3.6 & 0.2 & & & 0.3 & 0.8 & & 14.0 & 0.3 & 11.9 & & \\
\hline
\end{tabular}


List of Figure captions

Figure 1: Location map of Dalgety Bay, UK. Dashed line encompasses the area of the beach where the hot particles were found.

Figure 2: Hyperfocal, optical images of Dalgety Bay particles I - IX.

Figure 3: Backscatter SEM images of Dalgety Bay particles I - IX.

Figure 4: SEM-EDX element maps of surfaces of Dalgety Bay particles II, IV and VIII.

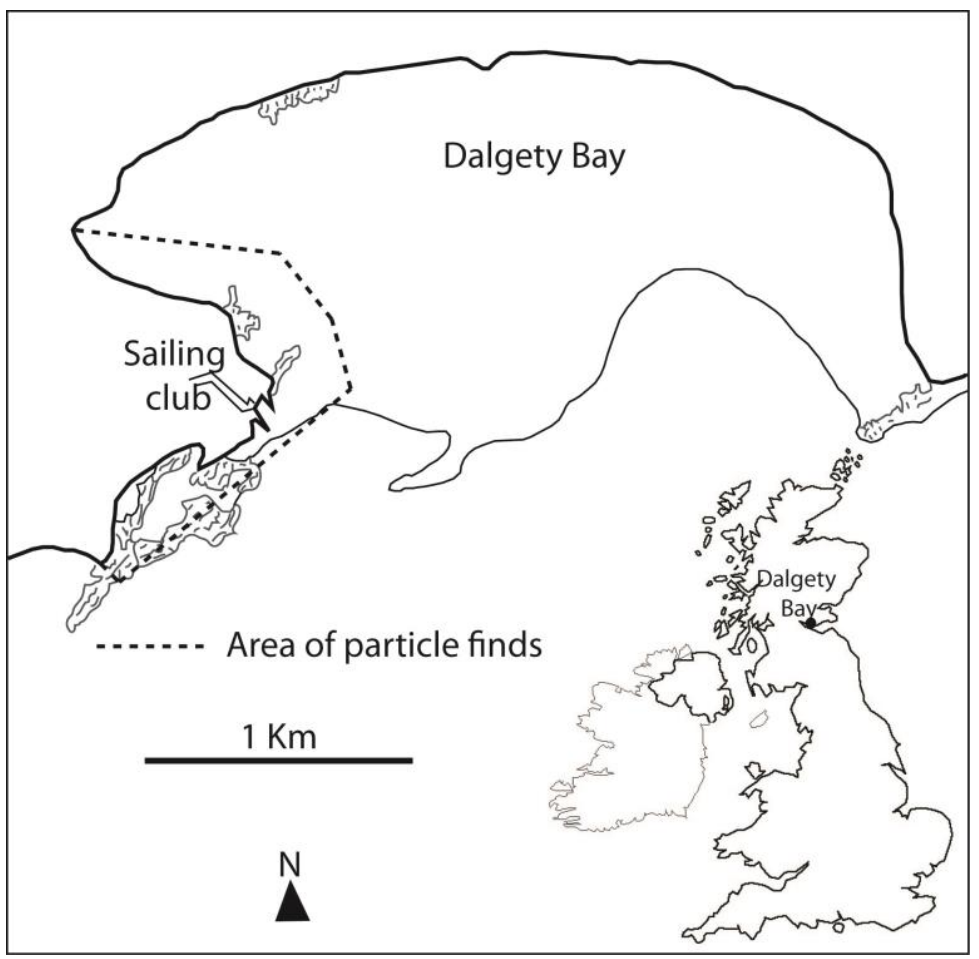

Figure 1 

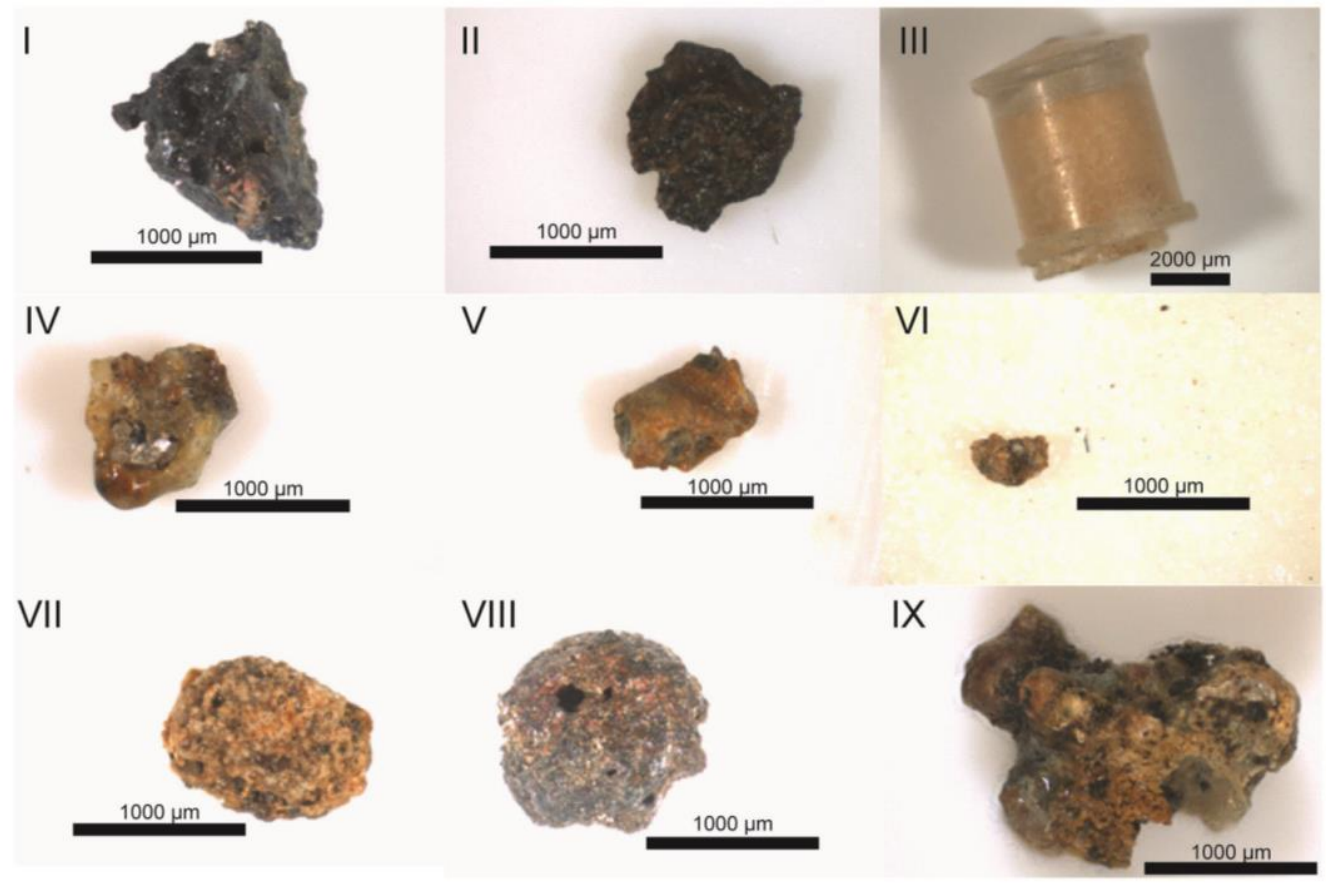

Figure 2

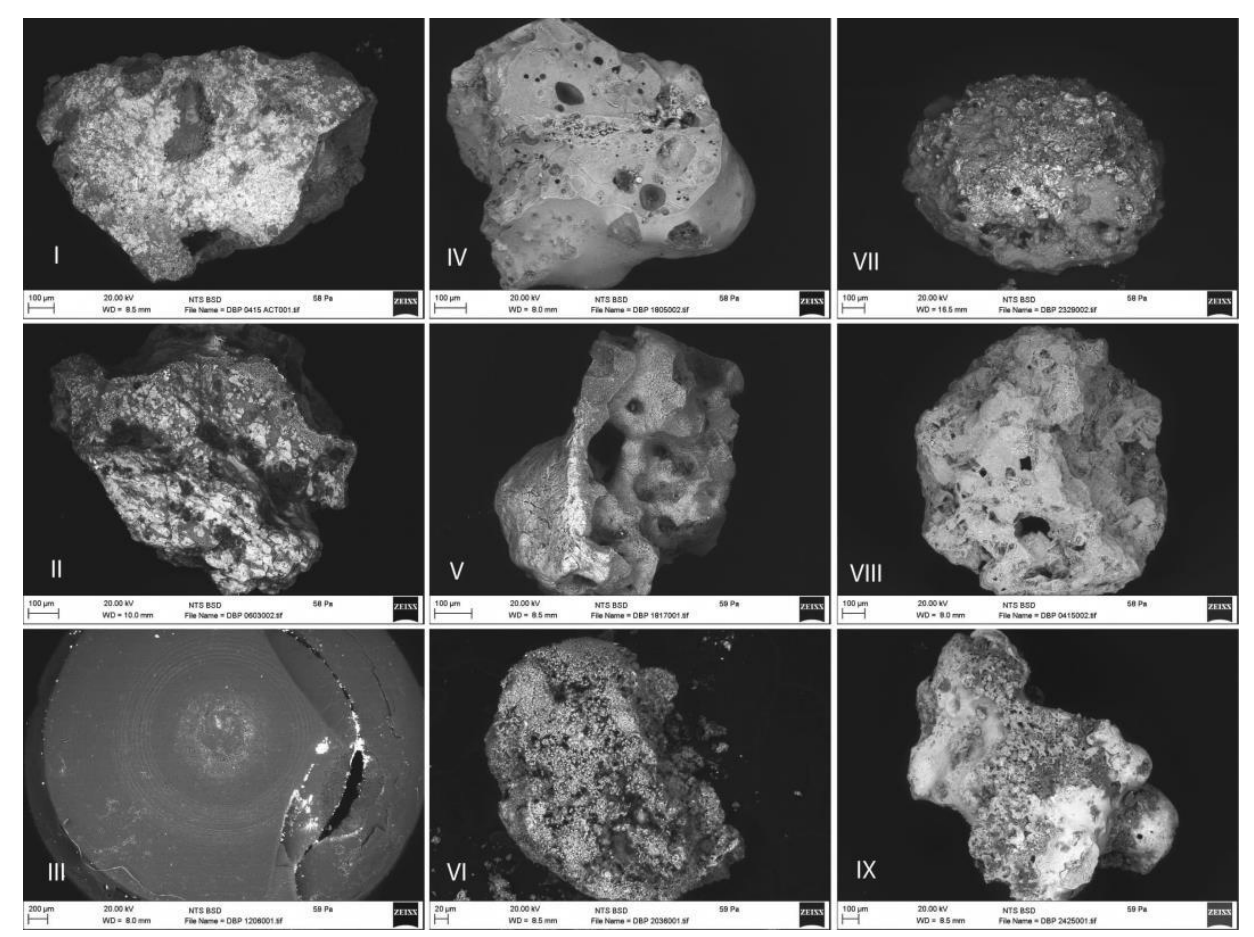

Figure 3 


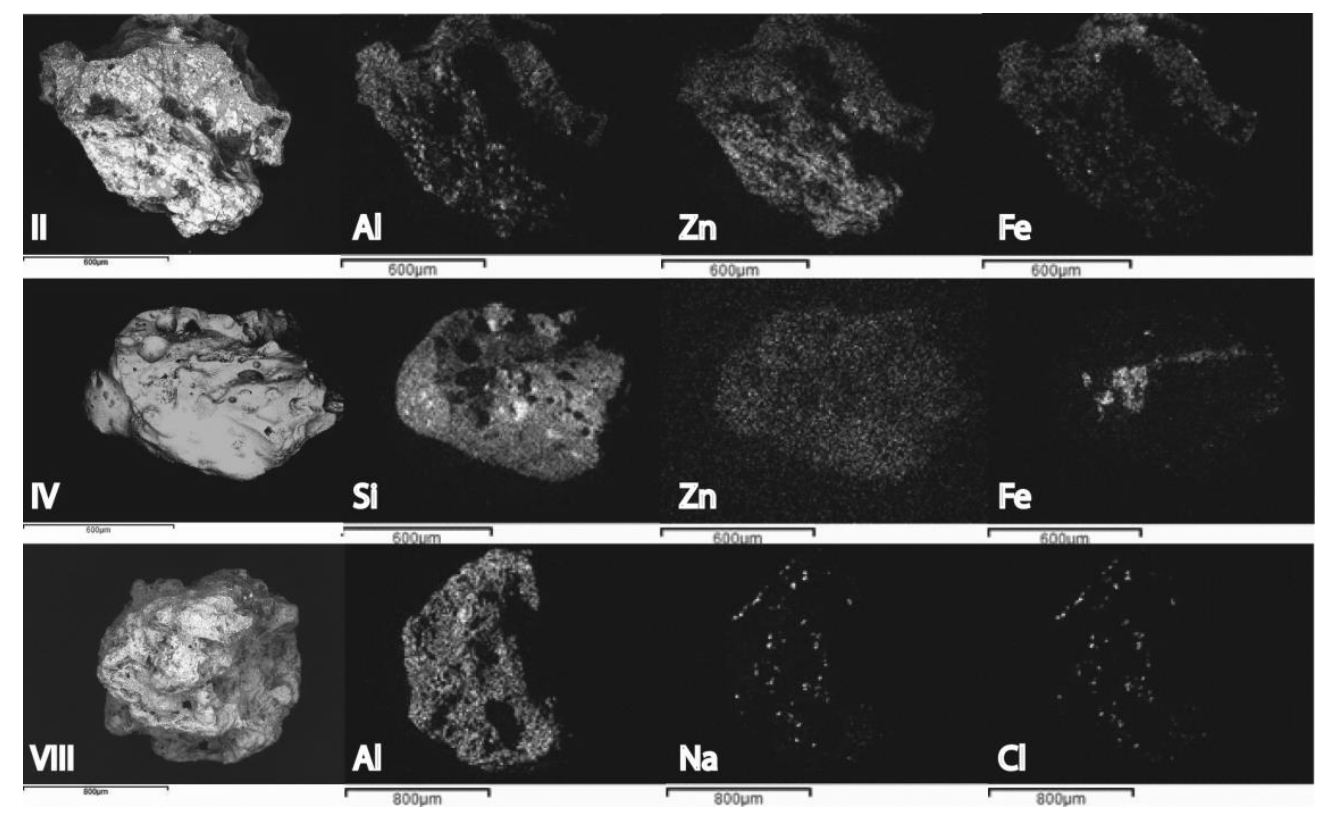

Figure 4 